\title{
POLÍTICA CRIMINAL E REEDUCAÇÃO DE AGRESSORES: UMA RESPOSTA ESTATAL PARA A REDUÇÃO DA VIOLÊNCIA DOMÉSTICA
}

\section{CRIMINAL POLICY AND REEDUCATION OF AGGRESSORS: A STATE ANSWER FOR THE REDUCTION OF DOMESTIC VIOLENCE}

ARTENIRA DA SILVA E SILVA

Pós-doutorado em Psicologia e Educação pela Universidade do Porto, Portugal (2014). Doutor em Saúde Coletiva pela Universidade Federal da Bahia (2005). Mestre em Saúde e Ambiente pela Universidade Federal do Maranhão (2000). Atualmente é professora associada e pesquisadora da Universidade Federal do Maranhão, ministrando aulas de Saúde Coletiva para graduações de diversos cursos da área da saúde da UFMA, além de ser docente e pesquisadora efetiva do Mestrado de Direito e Instituições do Sistema de Justiça da UFMA.

\section{CLÁUDIO ALBERTO GABRIEL GUIMARÃES}

Doutor em Direito Público pela Universidade Federal de Pernambuco (2004). Doutor em Direito pela Universidade Federal de Santa Catarina (2006). Mestre em Direito Público pela Universidade Federal de Pernambuco (2001). Especialista em Magistério Superior pelo Centro Universitário do Maranhão - UNICEUMA (2000). Atualmente é Professor Adjunto da Universidade Federal do Maranhão, Professor Pesquisador da Universidade Ceuma - UNICEUMA, da Escola Superior do Ministério Público do Maranhão e Promotor de Justiça do Estado do Maranhão. Pesquisador do CNPq e FAPEMA.Tem experiência na área de Direito, com ênfase em Direito Penal, atuando principalmente nos seguintes temas:Teoria da Pena: Fundamentação e Legitimação do Direito de Punir, Criminologia Crítica, Direitos Humanos e Dogmática Penal. 


\section{GABRIELLA SOUSA DA SILVA BARBOSA}

Mestre em Direito e Instituições do Sistema de Justiça da Universidade Federal do Maranhão - UFMA.

\section{RESUMO}

A Lei no 11.340/2006 - Lei Maria da Penha -, fruto de uma condenação da Corte Interamericana de Direitos Humanos ao Brasil, possui natureza marcadamente penal. Ocorre que a punição penal estatal, entendida apenas como a determinação de prisão do agressor, nos casos de violência doméstica, não vem encontrando efetiva resposta social quanto à diminuição dos casos albergados pela lei. Tal inefetividade está pautada, dentre outros fatores, às origens, complexidade e especificidades da violência doméstica e familiar contra a mulher no seio da sociedade. Nesse sentido, buscou-se a utilização da previsão legal de comparecimento do agressor a programas de recuperação e reeducação como a principal medida de urgência a ser deferida como mecanismo efetivamente capaz de diminuir a reincidência de agressores de violência de gênero, inclusive de fato possibilitando que eles compreendam o caráter criminoso de atos de violência contra a mulher em detrimento do que culturalmente introjetaram. Para tanto, foram utilizadas como procedimentos metodológicos as pesquisas bibliográfica e documental.

PALAVRAS-CHAVE: Lei Maria da Penha; Medida Protetiva de Urgência; Patriarcado; Reeducação; Agressor.

\section{ABSTRACT}

The Act n. ${ }^{0}$ 11.340/2006 - Maria da Penha's Law -is the result of a Inter-American Court of Human Rights' rule against Brazil and it has a noticeably criminal nature. The fact is that the state criminal punishment for gender domestic violence only considers punishmnt as the determination of the aggressor's arrest. In cases of domestic violence this understanding has not achieved effective social response towards the reduction of the cases ruled by the above mentioned law. Such ineffectiveness is 
based, among other factors, on the origins, complexity and specificities of domestic and family violence against women in different societies. In this regard the aggressor's attendance to recovery and re-education programs must be considered as the main urgent measure to be deferred as a mechanism effectively capable of reducing the recidivism of aggressors of gender-based violence, making it possible for the perpetrators do actually understand violence against women as crimes even though they have culturally assimilated these acts as being normal. For this, were used as methodological procedures the bibliographic and documentary researches.

KEYWORDS: Maria da Penha's Law; Urgent Protective Measures; Patriarchate; Reeducation; Aggressor.

\section{INTRODUÇÃO}

A criação da Lei no 11.340/2006, denominada Lei Maria da Penha, é reconhecida como um marco para a proteção de mulheres em casos de violência doméstica no país. Instituída por influência de uma condenação no caso Maria da Penha Maia Fernandes, originada na Corte Interamericana de Direitos Humanos contra o Estado Brasileiro, no ano de 2001, por omissão e negligência no enfrentamento das questões relativas à violência doméstica, em específico por descumprimento ao artigo $7^{\circ}$ da Convenção de Belém do Pará, assim como aos artigos $1^{\circ}, 8^{\circ}$ e 25 da Convenção Americana de Direitos Humanos, têm-se que a lei reflete um longo processo de luta dos movimentos feministas e organizações de mulheres ao longo de décadas no país ${ }^{1}$.

Sob o slogan "quem ama não mata", na década de setenta, intensificaram-se os debates contra a violência em ambiente familiar, com grande enfoque do tema nas agendas dos movimentos feministas. É na década de oitenta que a fortificação dos debates sobre a violência doméstica acaba por impulsionar ações governamentais em tal temática, a exemplo dos Conselhos Estaduais e Municipais de Direitos da Mulher

\footnotetext{
1 Para maiores detalhes sobre as origens da Lei 11.340/2006, pesquisar em Calazans e Corte (2011) e Dias (2007).
} 
de 1983, a criação do Conselho Nacional dos Direitos da Mulher e das delegacias especializadas no atendimento às vítimas de violência, ambos implementados a partir do ano de 1985, assim como a inclusão na Assembleia Constituinte de 88 do inciso I do artigo $5^{\circ}$ - igualdade entre os sexos - e do parágrafo $8^{\circ}$ ao artigo 226 - criação de mecanismos para coibir a violência no âmbito das relações familiares. ${ }^{2}$

É nesse contexto que, tomando força tanto na sociedade quanto nas pautas governamentais, a temática da violência doméstica passa a fazer cada vez mais pressão para a criação de uma medida legislativa de enfrentamento a este tipo de violência, que considerasse a situação de vulnerabilidade da mulher agredida. É, pois, quando o Projeto de Lei 4.559/2004 é sancionado em 2006, sendo a lei nomeada de Maria da Penha como a reparação simbólica a mesma, fruto da condenação supramencionada ao Estado brasileiro. Ocorre que, mesmo diante dos inegáveis avanços trazidos pela criação legislativa, como a retirada das agressões leves, abusos morais e psicológicos e demais crimes de menor potencial ofensivo da esfera dos Juizados Especiais Criminais e sua natureza jurídica marcadamente conciliatória - em prol da continuidade da família ${ }^{3}$-, segundo dados de 2010 , a cada dois minutos cinco mulheres ainda são espancadas no Brasil ${ }^{4}$.

Ademais, outras importantes inovações foram inseridas no âmbito da Lei no 11.340/2006: as medidas protetivas de urgência. Figura sui generis, de natureza jurídica ainda indefinida tanto pela doutrina quanto pela jurisprudência pátrias, são tais medidas, previstas entre os artigos 18 e 24 da lei, as de mais fácil acesso às mulheres que buscam o auxílio do poder estatal, sem necessidade de advogado, de modo a, por pedidos de proteção ao Judiciário, manter a integridade física, psicológica, sexual, patrimonial e moral da mulher vítima de violência em âmbito doméstico ${ }^{5}$.

Mesmo representando parcela majoritária do acesso judicial nos casos albergados pela Lei № 11.340/2006, tais medidas possuem apenas o condão de resguardar direitos da mulher agredida, o que, por si só não satisfaz o apelo social de punição do agressor e ou de qualquer medida que de fato possa prevenir a ocorrência

\footnotetext{
2 Sobre o tema, conferir os trabalhos do Centro Feminista de Estudos e Assessoria (2009) e Oliveira (2013)

${ }^{3}$ Cfr. Acre (2008).

${ }^{4}$ Dados constantes em Fundação Perseu Abramo/SESC (2010).

${ }^{5}$ Sobre o assunto Pires (2011).
} 
dos fatos trazidos emergencialmente a juízo, em especial pelo processo de naturalização da violência de gênero, que comumente leva o agressor a não perceber suas ações ou omissões como violência.

Mais preocupante, ainda, é que o incremento das possibilidades punitivas, previstas, por exemplo, nos artigos 17, 20, 41 a 44 da lei, que, por sua vez, também não têm se mostrado eficientes na seara de reeducação do agressor, visto que a possibilidade de retratação da vítima - a qual, muitas vezes se encontra em situação de dependência econômica e/ou psicológica do agressor ${ }^{6}$ - acabam por transformar a aplicação de todos os dispositivos legais em medidas meramente paliativas, em nada contribuindo para a condenação e consequente punição do agressor e, menos ainda, para sua conscientização e reeducação.

$\mathrm{Na}$ verdade, o que se tem percebido é que, em razão do baixíssimo número de ações penais interpostas, geralmente, a decretação de prisão nos casos de violência doméstica é uma forma de punir o agressor pela desobediência à medida protetiva aplicada, e não uma responsabilização direta pelo ato violento.

Para que se tenha uma ideia da não punibilidade dos agressores domésticos de violência contra a mulher, na Vara Especializada de São Luís do Maranhão, desde sua criação, em 2008, até o início de 2017, foram emitidas apenas 91 guias de execução.

Considerando-se que na referida vara tramitaram mais de 15000 processos no aludido período, evidencia-se a impunidade como tônica no trato da violência contra a mulher, que na prática continua sendo tratada como um crime de menor importância por ser perpetrado contra um ser humano naturalizado como infravalorado, cujo processo de assujeitação acaba pautado em uma amputação de tais mulheres no uso do poder ${ }^{7}$.

É diante deste complexo cenário, demarcado pela naturalização cultural, inclusive em âmbito institucional, percebendo-se a violência doméstica como uma violação de direitos humanos muito específica, que ocorre entre pessoas que possuem forte vínculo afetivo pretérito ou presente, assim como um fenômeno pandêmico, embebido pelo patriarcado na sociedade contemporânea, que se

\footnotetext{
${ }^{6}$ Sobre o assunto Almudena e Silva (2015).

${ }^{7}$ Maiores detalhes em Safiotti (2004).
} 
pretende analisar a possibilidade de aplicação automática do que previsto no artigo 45 da Lei Maria da Penha; a obrigatoriedade de comparecimento do agressor a programas de recuperação e reeducação, como a principal medida protetiva de urgência a ser deferida, por entendermos capaz de diminuir sensivelmente a reincidência em casos de violência doméstica.

\title{
2 POLÍTICA CRIMINAL FRENTE AO DIREITO PENAL CONTEMPORÂNEO
}

A expressão latina política criminal é de origem italiana, surgindo como uma crítica ao sistema punitivo, constante da obra "Dos delitos e das penas" de Cesare Beccaria, publicada nos idos de 1764. A partir de então inúmeros foram os estudos elaborados sobre política criminal, contudo, em 1899, com os escritos de Von Listz, chegou-se a um conceito que perdura até os dias de hoje, entendendo-a como a Ciência que norteia o poder punitivo estatal, assim como, também, fornece fundamentos jurídicos ao Direito Penal ${ }^{8}$.

Nesse longo caminhar a Política Criminal, portanto, passa, paulatinamente, a obter uma função de se utilizar das descobertas científicas advindas da Criminologia, de modo a auxiliar e reger as opções legislativas no âmbito do direito penal, podendose afirmar que hodiernamente:

\begin{abstract}
Pode-se conceituar a política criminal como a disciplina prático-valorativa que, com fundamento nos resultados obtidos pela criminologia, busca instrumentos para a prevenção da criminalidade, com influência direta não apenas na fase de elaboração legislativa, mas, especialmente, no momento de interpretação e de aplicação das normas constituídas, o que é feito por meio do fornecimento de indicadores axiológicos para a sistematização dogmática penal, estabelecendo-Ihe os fins teleológicos. (LUCA, 2009, p. 10).
\end{abstract}

Ocorre que, falar em Política Criminal frente ao Direito Penal contemporâneo requer reflexão acerca da crise que ambos vêm enfrentando quanto às suas finalidades sociais, incluindo-se, nesse ponto, a importância de se considerar pontuações oriundas da Criminologia. Especial trato e esmero acadêmico merece

\footnotetext{
8 Para um maior aprofundamento no tema, cfr. Dias e Andrade (1997), Cit (2010) e, por todos, Newburn (2007).
} 
ainda os crimes que ocorrem em ambiente domésticos ou entre sujeitos que possuam vinculação afetiva significativa pretérita ou presente.

No âmbito dos estudos criminológicos, a partir da década de 60 do século XX abriu-se uma nova perspectiva de análise da criminalidade e do controle social com vista a colocar em relevo o debate sobre como se mantém a autoridade em sociedades permeadas por conflitos sociais, ${ }^{9}$ sendo importante reafirmar que pouca atenção continua sendo dada para as questões afetas a vitimização da mulher em ambiente doméstico. ${ }^{10}$

Há que se ter por conta que a referida crise, a bem da verdade, é processo que veio sendo construído antes dos anos setenta e passa a se intensificar ao longo dessa década, quando é rompido um paradigma de um direito penal retributivo.

É, pois, nesse ponto, que se passa a indagar se um direito penal, consubstanciado por uma dogmática penal extremamente abstrata e alheia à realidade social tal como ainda se configura, seria eficaz no enfrentamento dos conflitos, ora ampliados pela crescente complexidade relacional trazida pela modernidade e pelas especificidades que circundam a violência intrafamiliar e ou doméstica, necessitando tanto de mais aproximação com a realidade quanto dos valores do contexto histórico que integra ${ }^{11}$.

$\mathrm{Na}$ verdade, entende-se que o Direito Penal enquanto potestade punitiva do Estado, quando do exercício efetivo do jus puniendi, ainda que pelos órgãos que compõem o Sistema Formal de Controle Social e, mesmo que fundamentado e limitado pela existência de um conjunto de normas primárias e secundárias, se encontra em crise. Trata-se, fundamentalmente, de uma crise de legitimidade, sendo recorrentes os questionamentos acerca da justificativa de recorrer o Estado à máquina penal, seu instrumento mais poderoso. Ademais, questiona-se, também a dogmática jurídica, a chamada "Ciência do Direito Penal" que passa por uma profunda crise de identidade, na qual o que se questiona é o próprio modelo a ser adotado e sua

\footnotetext{
9 Sobre o assunto, cfr. Azevedo (2008), Silva Sanchéz (2011), Miranda Santos (2013).

$10 \mathrm{Um}$ detalhado estudo sobre o tema pode ser encontrado em Newburn (2007, p. 300-317).

11 Sobre o tema, imprescindível a leitura de Zaffaroni (2001, p. 139-165) e Zaffaroni (2003).
} 
autêntica utilidade social, apontando-se, concomitantemente, para problemas de "legitimidade epistemológica", de validade científica ${ }^{12}$.

Por outro lado, mesmo diante da referida crise, a opção abolicionista não se mostra sequer possível ou coerente de ser aplicada em crimes de violência doméstica, uma vez que a paridade de vulnerabilidade entre as partes, pressuposto essencial de um processo conciliatório com ou sem a intervenção do $\mathrm{Estado}^{13}$, está explicitamente ausente, frente ao elo de vinculação afetiva pretérita ou presente entre vítima e agressor e frente à ciclicidade típica deste tipo de violência, que não ocorre uma única vez e ou isoladamente. Ou seja, a crise na qual se inserem tanto a dogmática penal, quanto a política criminal, e mesmo a criminologia, nos tempos atuais, vai para além de demonstrar uma problemática tautológica e sem resultados, como leciona de modo límpido Roxin (2006, p. 28):

Conciliações sem a intervenção do Estado, como defende o abolicionismo, conseguirão substituir o direito penal de modo tão precário quanto o poderá fazer um puro sistema de medidas de segurança; também uma vigilância mais intensa dos cidadãos pode, enquanto ela for permitida, ter uma certa eficácia preventiva, mas não conseguirá tornar o direito penal supérfluo.

Mostra-se, portanto, a referida crise, mais como um reflexo das antinomias entre princípios e valores institucionalizados pelo moderno Estado de Direito, tais como liberdade e segurança, indo além da constituição de um fenômeno negativo, mas sim transformando-se em motor propulsor de uma evolução do Direito Penal.

Em suma, acredita-se que o Direito Penal clássico não mais responde a contento às complexidades trazidas pela crescente dinâmica instrumentalizada racionalmente por hegemônicos paradigmas tecnológicos, científicos e econômicos, fazendo-se necessária a reconstrução deste para além das vertentes teóricas isoladas, quer sejam abolicionistas ou punitivistas. Talvez, uma vertente mais teleológica, que comungue as diversas perspectivas teóricas, que atualize a finalidade do Direito Penal e de suas penas ${ }^{14}$, que resgate o caráter pedagógico e preventivo

\footnotetext{
12 Denso estudo sobre o tema foi realizado por Andrade (1997) e Yacobuci (2000).

${ }^{13}$ Método de solução de conflitos desenvolvido por um terceiro facilitador, de modo a incentivar as partes a se autocomporem por meio de um acordo. É considerado mais apropriado para demandas que necessitem apenas de soluções rápidas e mais objetivas, nos quais os problemas envolvam relações superficiais entre as partes (GRINNOVER, 2010, p. 4)

${ }^{14}$ Sobre os fins das penas, detalhado estudo em Guimarães (2007).
} 
que deve permear qualquer sistema de controle social, com a missão maior de concorrer para a eficácia e efetividade do disciplinamento social ${ }^{15}$.

É, portanto, quando da discussão referente às finalidades desse novo Direito Penal - mais aberto e flexível -, frente à crise de legitimidade enfrentada pelo mesmo, que se mostra fulcral a discussão quanto à política criminal, uma vez que é esta a via encontrada para o recebimento das valorações e princípios do contexto sócio-cultural que intenta reger. Nesse sentido, Borja Jimenéz (2003, p. 115-116, tradução nossa) pontua: "Se postula então em favor de um sistema de Direito Penal aberto, isto é, suscetível de receber as valorações que moldam seus conceitos e princípios pela via político-criminal."

Nunca é demais lembrar as lapidares lições de Durkheim (1995), para quem a estrutura política de uma sociedade nada mais é do que o modo pelo qual os diferentes segmentos que a compõem tomaram o hábito de viver uns com os outros ${ }^{16}$. Nessa perspectiva, o crime é encarado como fenômeno que faz parte da sociedade ${ }^{17}$, devendo, contudo, ser mantido em níveis toleráveis.

Nessa perspectiva e mesmo levando em consideração o amplo espectro dos problemas sociais representado pela criminalidade, supera-se a questão se o crime pode ou-não ser definitivamente eliminado para focar a atenção em como ele deve ser reduzido ao mínimo ou a padrões aceitáveis. Nesse passo é importante entender o papel que a política exerce nas sociedades modernas ${ }^{18}$.

Portanto, é diante da referida complexidade social dos delitos contemporâneos, e nesse ponto se inclui a violência doméstica - a qual se vê pautada

\footnotetext{
15 Interessante abordagem do tema, cfr. Diniz Neto (2010).

16 Para Durkheim (1995), caso as relações sejam tradicionalmente estreitas, os segmentos tendem a se confundir ou, de modo contrário, tendem a se distinguir, na medida em que tais relações se dissipam. Assim, o criminoso não aparece mais como um ser radicalmente insociável, espécie de parasita, corpo estranho e alienígena, introduzido no seio da sociedade; contrariamente, constitui um agente regular da vida social. Desse modo, crime e violência necessitam ser encarados sob uma perspectiva realística e da qual não se pode fugir, mas preveni-los e deixa-los em níveis toleráveis.

17 Segundo Durkheim (1995, p. 61), “o crime é, pois, necessário; ele se liga às condições fundamentais de toda a vida social e, por isso mesmo, tem sua utilidade; pois estas condições de que é solidário são elas próprias, indispensáveis à evolução normal da moral e do direito. [...] Ora, se não existissem crimes, esta condição não se verificaria; pois tal hipótese supõe que os sentimentos coletivos teriam alcançado um grau de intensidade sem exemplo na história. Nada é bom nem indefinidamente, nem desmedidamente. [...] Para que evolua, é preciso que a originalidade individual possa vir a lume; ora, para que a originalidade do idealista, que sonha ultrapassar seu século, se manifeste, é necessário que a do criminoso, que está abaixo do seu tempo, seja possível. Uma não existe sem a outra".

18 Sobre o tema, imprescindível a leitura de Christie (2007). Cfr., também, Moraes (2006).
} 
nas relações de gênero -, que se faz fundamental a percepção de quais políticas criminais estão a nortear a criação legislativa e a própria dogmática penal. Ademais, deverá tal política, nos casos de enfrentamento da violência a mulheres em ambiente doméstico, estar pautada nos estudos criminológicos ${ }^{19}$ ligados a tal fenômeno delitivo, de modo a delinear a atuação dos Poderes Executivo, Legislativo e Judiciário, este último com a interpretação transdisciplinar e aplicação efetiva da Lei Maria da Penha, evitando-se as distorções que acabam por impedir o seu alcance previsto pelo legislador, em função de hipossuficiência técnica daqueles que a operam.

\title{
3 DAS ORIGENS E ESPECIFICIDADES DA VIOLÊNCIA DOMÉSTICA E FAMILIAR CONTRA A MULHER
}

Segundo dados de 2007 da Organização Mundial de Saúde - OMS, que foram colhidos através de entrevista de 25.000 (vinte e cinco mil) mulheres em 10 países, constatou-se que entre $25 \%$ a $50 \%$ das entrevistadas haviam sido vítimas de violência doméstica severa ou moderada no ano anterior ${ }^{20}$.

Os dados alarmantes em âmbito mundial ajudam a descortinar a intensa e crescente naturalização do tema da violência doméstica. A fim de dar mais clareza ao estudo ora intentado, importantes são as conceituações trazidas por Saffioti (2004, p. 69-71) quanto da diferenciação entre violências de gênero, doméstica e familiar.

\begin{abstract}
Como se trata de relações regidas pela gramática sexual, podem ser compreendidas pela violência de gênero. Mais do que isto, tais violências podem caracterizar-se como violência doméstica, dependendo das circunstâncias. Fica, assim, patenteado que a violência de gênero pode ser perpetrada por um homem contra outro, por uma mulher contra outra. Todavia, o vetor mais amplamente difundido da violência de gênero caminha no sentido homem contra mulher, tendo a falocracia como caldo de cultura. Não há maiores dificuldades em se compreender a violência familiar, ou seja, a que envolve membros de uma mesma família extensa ou nuclear, levando-
\end{abstract}

19 Sobre o assunto, Radford e Stanko (2009, p. 402-408), para quem: "Como feministas nós sustentamos que a violência sexual é usada pelos homens como um meio para assegurar e manter as relações de dominância masculina e subordinação das mulheres, as quais são centrais na ordem social patriarcal. Reconhecemos que o patriarcado é perpassado e está em estreita interação com outras estruturas de poder e suas deficiências, tais como raça, classe, idade e status social". Radford e Stanko (2009, p. 402, tradução nossa)

${ }^{20}$ Cfr. Celmer e Azevedo (2007) 
se em conta a consaguineidade e a afinidade. Compreendida na violência de gênero, a violência familiar pode ocorrer no interior do domicílio ou fora dele, embora seja mais frequente o primeiro caso.

A Lei no 11.340/2006, por sua vez, em seu artigo 5, passa a considerar tanto a violência doméstica quanto a familiar contra a mulher toda "ação ou omissão baseada no gênero que the cause morte, lesão, sofrimento físico, sexual ou psicológico e dano moral ou patrimonial", na unidade doméstica, no âmbito da família ou pelo convívio presente ou passado com alguém com quem tenha havido ou haja relação íntima de afeto.

Trouxe, ainda, o legislador, categorização das formas de violência albergadas pela lei, no artigo $7^{\circ}$, quais sejam: física, psicológica, sexual, patrimonial e moral. Nesse ponto, importante destacar as lições de Dias (2007, p. 46):

Preocupou-se o legislador não só em definir a violência doméstica e familiar.
Também especificou suas formas, até porque, no âmbito do Direito Penal,
vigoram os princípios da taxatividade e da legalidade, sede em que não se
admitem vagos. Ainda assim, o rol trazido pela Lei não é exaustivo, pois o art.
$7^{\circ}$ utiliza a expressão "entre outras". Portanto, não se trata de numerus
clausus, podendo haver o reconhecimento de ações outras que configurem
violência doméstica e familiar contra a mulher. As ações fora do elenco legal
podem gerar adoção de medidas protetivas no âmbito civil, mas não em sede
de Direito Penal, pela falta de tipicidade. (grifo nosso).

Outrossim, o que se percebe quando de uma análise mais acurada no âmbito da violência doméstica e familiar contra mulheres, em relação às medidas albergadas pela Lei Maria da Penha, é de que tais mulheres quando acessam o Judiciário, em sua maioria o fazem através das Medidas Protetivas de Urgência - figuras assecuratórias da integridade física, moral e patrimonial das vítimas, as quais não possuem o condão de punir o agressor.

Tal facilidade na aplicação das mesmas em detrimento das outras determinações previstas na Lei no 11.340/2006, dá-se não apenas pela agilidade destas, que são encaminhadas ao Judiciário no expediente das delegacias, como também pela desnecessidade de capacidade postulatória - acompanhamento de um 
advogado -, assim também da segurança dada às mulheres de que o agressor somente será preso caso desobedeça a medida ${ }^{21}$.

Neste ponto mostra-se interessante analisar as origens da violência doméstica, a fim de se debater se a aplicação de tais medidas de modo isolado como acontece na maioria das varas especializadas - se faz de modo eficaz não apenas para cessar a violência contra a mulher vitimada, mas de modo a impedir que o mesmo agressor volte a reincidir contra esta ou outras mulheres.

Inicialmente, cabe desmistificar o senso comum de que a mulher vítima de violência doméstica "gosta de apanhar". Têm-se que a construção das subjetividades, tanto de mulheres quanto de homens, se dá por meio da vinculação dos membros da sociedade de acordo com o local por eles ocupados na estrutura social.

Nesse sentido, a mulher vítima de violência doméstica - afora as complexidades trazidas a nível psicológico pela conflituosidade entre o afeto e a agressão, a exemplo da Síndrome da Mulher Agredida e do Transtorno PósTraumático - vê-se alocada em um sistema criador de subjetividades e de identidades sociais pautado pelo entrecruzamento dos eixos patriarcado, racismo e capitalismo. Em suma:

\begin{abstract}
Desde a célebre frase de Simone de Beauvoir, "não se nasce mulher, tornase mulher", os movimentos feministas têm criticado estereótipos de gênero que condicionam o corpo feminino a um tipo específico de papel social, de personalidade, de profissões, de espaço público, ou de "natureza" materna. Haveria um corpo a partir de cujo sexo biológico - "natural" - um papel de gênero feminino seria construído culturalmente; daí a afirmação acerca de tornar-se mulher em vez de nascer-se mulher. Essa ideia - bastante revolucionária há menos de um século - penetrou o espaço político-cultural de nosso tempo de forma tão poderosa que é muito raro encontrar alguém que afirme categoricamente a existência de um só papel de gênero natural a homens e a mulheres, universal, baseado no sexo biológico e descolado da cultura. (NORONHA; NORONHA, 2016, p. 753).
\end{abstract}

Assim sendo, conclui-se que ambos os sexos biológicos, homem e mulher, passam a ter suas subjetividades determinadas socialmente, pelas possíveis relações com os eixos supracitados. O que se percebe quando da análise dos mesmos patriarcado, racismo e capitalismo - é uma demarcada relação de poder, a qual, por uma concepção foucaultiana, não se resume às macroesferas, representando-se,

${ }^{21}$ Sobre o assunto, mais detalhadamente, Pires (2011). 
inclusive nas relações privadas, da qual a mulher é historicamente figura vulnerabilizada 22 .

É público e notório que este processo é cotidiano e infinito, pensando-se o poder não como um objeto do qual se possa realizar uma definitiva apropriação, mas como algo que flui, que circula nas e pelas relações sociais. Esta instabilidade do poder, ou melhor, esta rotatividade dos poderosos não ocorre apenas na micropolítica, mas também na macropolítica. A malha fina e a malha grossa não são instâncias isoladas, interpenetrando-se mutuamente, uma se nutrindo da outra. (SAFFIOTI, 2004, p. 13).

No Brasil, país de colonização portuguesa, extremamente marcado pelo patriarcalismo das relações parentais advindas da cultura da metrópole Portugal - a qual se via embebida pela tradição feudal e religiosa de demonização e menosprezo da figura feminina -, se percebe, no ambiente doméstico do século XVIII que o chamado pátrio poder se vê ilimitado, mantendo-se o grupo familiar isolado de qualquer perturbação, limitação ou freios para a sua tirania ${ }^{23}$.

É, ainda, no seio das relações sociais e da faceta preponderante do patriarcado nas mesmas, que o direito reflete as concepções sociais do passado, as quais, indubitavelmente, ainda respingam na postura e identidades subjetivas dos sujeitos que as compõem na atualidade.

Tamanha naturalização da violência em ambiente doméstico e familiar se vê refletida, pois, no Sistema de Justiça. Representação disso são as Medidas Protetivas de Urgência - MPUs: apesar de representarem 60\% de toda a atuação dos juizados especializados em violência doméstica na jurisdição nacional, ainda hoje, 10 anos após o sancionamento do diploma legal, representam enorme querela para a doutrina, jurisprudência e jurisdicionados diante da indefinição de sua natureza jurídica ${ }^{24}$.

Apesar do texto da Lei Maria da Penha possuir caráter predominantemente penal, inclusive com a definição de competência subsidiária das varas criminais na ausência dos juizados especializados na respectiva comarca, o que rege sua aplicação é a meta de proteção máxima e integral da mulher, indo-se para além do

\footnotetext{
22 Maior aprofundamento em Sauáia e Alves (2016), Saffioti (2003) e Alvarenga (2010).

23 Sobre o assunto, imprescindível a leitura de Holanda (1995).

24 Este e mais dados podem ser encontrados em CNJ (2010).
} 
caráter meramente simplista e punitivista e buscando-se seu empoderamento e consciência de seus direitos.

É diante disso e da própria diversidade de medidas constantes na lei - as quais vão desde a proibição de condutas (artigo 22, III), passando pela determinação de alimentos (artigo 22, V), e até mesmo a suspensão de procurações (artigo 24, III) - que há forte divergência doutrinária acerca da natureza cível, penal, mista ou mesmo administrativa das MPUs.

Ocorre que tamanha indefinição impacta negativamente os envolvidos nas demandas referentes às medidas, uma vez que a praxe jurídica tem demonstrado que os operadores do direito, ao não saberem qual recurso utilizar diante da concessão ou negação das MPUs, também acabam por desconhecer o órgão competente para julgamento dos mesmos, uma vez que em alguns momentos os recursos são penais e em outros cíveis, sem critérios para que se impetre um ou outro. Para agravar a situação, existem muitas incertezas e falta de uniformização acerca de que procedimentos são necessários para encerramento seguro da vigência de Medidas Protetivas de Urgência frente à não proposição de uma ação penal ou cível posterior. (ANDRADE SILVA, 2013)

É diante da omissão legislativa e doutrinária que a banalização do instrumento mais usado no país para proteger mulheres em situação de violência doméstica e familiar chega em seu ápice: a quase totalidade dos tribunais nacionais, inclusive o Superior Tribunal de Justiça, continuam silentes quanto à natureza jurídica das MPUs.

\footnotetext{
Não é aceitável que cada tribunal possua um procedimento diferenciado a respeito das medidas protetivas de urgência, já que, pelo princípio constitucional do devido processo legal deve-se garantir o contraditório e a ampla defesa, em suas dimensões material e substancial àquele que está sendo processado. Ora, se até mesmo o órgão jurisdicional varia o procedimento aplicável às medidas protetivas, é evidente que o réu e seu causídico desconhecerão o ato jurídico adequado à sua defesa. (ANDRADE SILVA, 2013, p. 24)
}

Ignorando-se os prejuízos causados às partes e os impactos aos princípios constitucionais do devido processo legal e contraditório, assim também da própria unirrecorribilidade das decisões, a jurisprudência continua a embasar a aceitação de recursos no julgamento das Medidas Protetivas de Urgência no entendimento 
individual de cada julgador, mesmo que tal instrumento seja o de uso mais expressivo da Lei no 11.340/2006.

Torna-se possível apreender que as origens da violência do homem à mulher em ambiente familiar e/ou doméstico estão fortemente ligadas às relações de poder estabelecidas em âmbito privado, espelhadas e introjetadas no âmbito público, inclusive na atuação do próprio Sistema de Justiça, às quais se veem embebidas por fatores sócio-histórico-culturais, havendo, portanto, de serem evidenciadas e dirimidas através da própria recomendação da OEA, ao condenar o Brasil no caso Maria da Penha Maia Fernandes, prevendo a necessidade de qualificação continuada dos operadores do Sistema de Justiça para que possam de fato adquirir conhecimento transdisciplinar sócio-psicológicos sobre todas as complexas especificidades da violência de gênero, a fim de poder prevení-la, coibí-la e finalmente erradicá-la, conforme compromisso internacionalmente assumido pelo país. Cumprir com os compromissos internacionais assumidos pelo Brasil no que tange ao combate à violência de gênero implica em encarar com profundidade e de modo resolutivo a temática da violência contra a mulher em ambiente doméstico.

\section{COMPARECIMENTO DO AGRESSOR A PROGRAMAS DE RECUPERAÇÃO E REEDUCAÇÃO COMO A PRINCIPAL MEDIDA PROTETIVA DE URGÊNCIA A SER DEFERIDA PELO JUÍZO}

A Lei Maria da Penha prevê em seu artigo 35, inciso V, a possibilidade de a União, o Distrito Federal, os Estados e os Municípios criarem e promoverem centros de educação e reabilitação dos agressores. Outrossim, no artigo 45 da mesma lei, impõe-se a modificação do artigo 152 da Lei oㅜ 7.210/84 - Lei de Execuções Penais, acrescentando-se um parágrafo único com o seguinte teor:

Art. 45. O art. 152 da Lei no 7.210, de 11 de julho de 1984 (Lei de Execução Penal), passa a vigorar com a seguinte redação: "Art. 152. [...] Parágrafo único. Nos casos de violência doméstica contra a mulher, o juiz poderá determinar o comparecimento obrigatório do agressor a programas de recuperação e reeducação. 
Nos dizeres do relatório das "Diretrizes para Implementação dos Serviços de Responsabilização e Educação de Agressores", das Secretarias de Políticas para Mulheres e de Enfrentamento à Violência contra as Mulheres da Presidência da República, de 2008, tais centros deverão ser um local de atendimento ao agressor, tendo-se por objetivo precípuo dos serviços prestados no mesmo o acompanhamento das penas e decisões proferidas pelo juízo ao agressor, possuindo um caráter pedagógico e obrigatório, não assistencial ou de tratamento ${ }^{25}$.

Nesse ponto, fundamental que se utilizem os dados colhidos e as respectivas análises qualitativas dos mesmos quando da análise do perfil do agressor de mulheres e crianças em situação de violência doméstica. Inúmeros estudos ou mesmo estatísticas em que se tenta traçar o perfil do agressor revelam, contrariamente ao que se poderia pensar em sede de senso comum, que mesmo as atitudes mais extremadas, redundando no feminicídio, dificilmente representam um perfil psicopatológico do agressor, sendo sua conduta expressão brutal do sentido de propriedade pautado por forte patriarcado, expresso principalmente pelo sentimento de posse e de poder do homem em relação à mulher ${ }^{26}$.

A título de exemplificação, tomem-se os resultados colhidos por Martins (2013, p. 78), quando da tentativa de encontrar uma generalização de perfis psicopáticos em homens encarcerados devido à violência doméstica na cidade de Lisboa:

\footnotetext{
Garrido descreve a "tríade letal" que caracteriza o psicopata, sendo que nesta insere-se a ausência de remorsos e o experienciar de sentimentos superficiais em relação a terceiros. Não constatámos esta realidade na nossa amostra, na medida em que apenas 3 sujeitos (27.3\%) referem não sentir remorsos pelas suas atitudes. Relativamente à impulsividade, a nossa amostra compreende apenas 4 sujeitos (36.4\%) que se reconhecem como tal.
}

Considere-se assim que os Centros de Educação e Reabilitação do Agressor devem trabalhar, não por um viés punitivista, nem patologizador ou vitimizador daquele que comete agressão contra mulher em ambiente doméstico, mas sim utilizando uma perspectiva feminista de gênero, contribuindo para o reconhecimento

${ }^{25}$ Cfr. Presidência da República (2008, p. 1).

${ }^{26}$ Saffioti (2001). 
de suas atitudes como violência, favorecendo a percepção de responsabilização dos agressores pela violência cometida, de modo a descontruir estereótipos de gênero e assim contribuir efetivamente para a prevenção deste tipo de crime, dando eficácia às Medidas Protetivas de Urgência ${ }^{27}$. No mesmo sentido:

O processo de reeducação e ou terapêutico revela-se duplamente útil, pois, ao mesmo tempo em que intervém de maneira ampla, individual e singular, curando as dores emocionais de agressores e agredidos, atua impedindo a reprodução comportamental, rompendo assim com o ciclo vicioso que se estabeleceu em que violência gera violência. Este contribui, portanto, de forma profilática, a danos inimagináveis no que tange ao comportamento e ao psiquismo de gerações futuras. (SAUAIA; ARRUDA; MELO, 2011, p. 7).

O que se percebe é que, aliado às penas previstas na Lei Maria da Penha ou mesmo à instituição das Medidas Protetivas de Urgência, a inclusão da obrigatoriedade de comparecimento dos agressores a tais centros de educação e reabilitação pode de fato constituir a principal medida a possibilitar que se alcance maior eficácia dos objetivos do diploma legal, uma vez que o enfrentamento das alocações sociais e significações de gênero construídas histórica, cultural e socialmente poderão ser resignificadas ideativamente e reintrojetadas emocionalmente pelo agressor, em última análise contribuindo inclusive para sua proteção, evitando que ele reincida nos crimes que antes ele sequer reconhecia como atos de violência ${ }^{28}$.

Repise-se, nesse ponto, que o próprio texto da Lei Maria da Penha em seu artigo 19 , parágrafo $2^{\circ}$, diante dos fins sociais aos quais ela se destina e do preceito constante em seu artigo $6^{\circ}$ de compreensão da violência doméstica enquanto violação aos direitos humanos, prevê a possibilidade de substituição ou cumulação das medidas protetivas intentadas por outras de maior eficácia - dentre as quais se inclui a proposição do presente estudo, uma vez que a reeducação do agressor acaba por se mostrar mais consentânea à ressignificação da violência por este e impedimento de sua reincidência.

Como bem relembra Andrade (2005, p. 79), quanto da funcionalidade do sistema de justiça criminal, percebem-se contrariedades entre as funções declaradas

${ }^{27}$ Cfr. Presidência da República (2008, p. 2).

${ }^{28}$ Nesse sentido, Pires (2011). 
e as latentes no e pelo mesmo. Para além de um déficit histórico no cumprimento das promessas declaradas pelo discurso oficial, o que redunda na crise de legitimidade do Direito Penal acima analisada, há também o cumprimento de funções latentes, inversas àquelas declaradas, o que se percebe claramente quando da análise da aplicação da Lei Maria da Penha. Corroborando tal posicionamento:

\begin{abstract}
Sendo assim, em uma primeira análise já se verifica que a pena de prisão não tem o condão de solucionar a raiz do problema, que necessitaria de medidas extrapenais, ou seja, de cunho assistencial, a fim de que o agressor seja encaminhado a tratamento psicológico, de recuperação do alcoolismo e outros vícios, a grupos de conscientização, entre outras medidas. O sistema penal, nesses casos, atua grande parte das vezes de forma simbólica e, inclusive, de maneira maléfica em relação aos envolvidos, eis que, a prisão, via de regra, conforme já analisado anteriormente, devolve para a sociedade cidadãos ainda mais perigosos. (SANTOS; SANTOS, 2013, p. 14).
\end{abstract}

Outrossim, a utilização isolada dos mecanismos legais das medidas protetivas de urgência não tem demonstrado eficácia no enfrentamento a longo prazo da violência doméstica, surtindo, sim, efeito contrário ao esperado, dado o simbolismo que as mesmas têm adquirido.

Destaque-se que o objetivo de tais medidas tem sido percebido como meramente assecuratório dos direitos imediatos da mulher. No entanto, o Estado sequer possui condições fáticas de vigiar indistintamente e a longo prazo o cumprimento da medida a todas as mulheres. Assim, tal deferimento não cumpre de modo efetivo com o discurso oficial do diploma legislativo, vez que não trabalha na raiz do problema, pois não se está buscando a proteção mais ampla possível dos bens jurídicos do qual a mulher é titular, assim como não se está cumprindo o objetivo de a empoderar e de seguramente resguardá-la da violação ininterrupta de seus direitos ${ }^{29}$.

É diante deste contexto, concebendo-se a política criminal como parte integrante de uma política de Estado e diante da ineficiência e até mesmo da deslegitimidade que a aplicação da lei em caráter meramente simbólico podem causar frente à sociedade, que se propõe que o Judiciário passe a incorporar com mais frequência o disposto no artigo 45 da Lei Maria da Penha, como principal medida protetiva a ser deferida, enquanto Política Criminal Extrapenal capaz de trabalhar a

29 Para maior aprofundamento, Santos e Santos (2013), Pires (2011). 
situação de violência doméstica com a profundidade, complexidade e especificidade necessárias, pautada no real enfrentamento do problema e de suas soluções.

\section{CONCLUSÃO}

Analisando-se a construção da Lei Maria da Penha, o que se percebe é que a mesma é fruto de um longo período de lutas de movimentos feministas e outros grupos organizados da sociedade civil em prol da tutela dos direitos sexuais, morais, psicológicos, patrimoniais e, principalmente, de não discriminação e de garantia de integridade física e psicológica de mulheres vítimas de violência em âmbito familiar e doméstico.

É com a condenação do Estado brasileiro pela Corte Interamericana de Direitos Humanos que os projetos de lei que já tramitavam no Poder Legislativo referentes à violência doméstica acabam ganhando maior impulso, culminando na Lei no 11.340/2006, apelidada de Maria de Penha em reparação simbólica à mesma, devido à referida condenação da corte internacional.

A partir da implementação da lei o que se percebe é que a sua aplicação se mostra majoritária nos casos de Medidas Protetivas de Urgência. Sendo tais medidas de natureza sui generis, as mesmas caracterizam-se pelo seu caráter assecuratório dos direitos da mulher agredida, inexigindo-se acompanhamento de advogado para sua postulação - uma vez que são enviadas ao juiz quando da denúncia nas delegacias -, assim também do não imediatismo na prisão ao agressor, o qual apenas será responsabilizado caso desobedeça a medida. São tais condições as que mais justificam a popularidade de tais medidas, frente às demais alternativas aplicáveis pelo texto legal.

Ocorre que o deferimento isolado de tais medidas protetivas de urgência, até por não ser o seu objetivo, não corresponde aos fins da lei, a qual se pauta por um viés protetivo e empoderador da mulher, assim também como não se adequa ao anseio social para que tais agressores, além de serem responsabilizados pelos seus atos possam compreender o caráter criminal de suas ações, frente à naturalização da 
violência de gênero introjetada cultural e psicologicamente, e assim possam não reincidir na prática delituosa.

É nesse sentido que se faz importante a análise da política criminal, uma vez é que a mesma responsável pela utilização dos estudos e conclusões da criminologia a auxiliar a atividade legislativa e a dogmática penal. Frente à referida crise do Direito Penal, a qual se apresenta tanto como uma crise de legitimidade do Direito Penal, quanto de identidade da Ciência do Direito Penal, o estudo e a percepção da política criminal se faz mais essencial ainda, uma vez que o Direito Penal passa a estar aberto a rever valores e princípios a fim de subsistir frente a tal crise.

Assim sendo, diante do enfrentamento da Lei Maria da Penha e da condição de violência doméstica e familiar contra mulheres o que se percebe é que o agressor, longe de ser uma figura comprometida psicopatologicamente, traz introjetados e naturalizados comportamentos que de fato constrangem, humilham, controlam e afetam a saúde psicológica da mulher vítima, percebida pelo seu agressor como de sua "propriedade".

Diante disso que se observa que o uso exclusivo das medidas protetivas de urgência ou mesmo da culminância da prisão ao agressor, para além do caráter simbólico da lei, não atinge suas finalidades de evitar a reincidência deste homem agressor contra a vítima ou outras mulheres, uma vez que as concepções de poder e gênero ao qual fora influenciado ao longo de toda a vida permanecerão inabaladas.

A partir de então, é que se propõe aos operadores do direito a mais ampla aplicação do artigo 45 da Lei Maria da Penha, qual seja, a obrigatoriedade de comparecimento do agressor a centros de educação e reabilitação, de modo a proporcionar uma efetiva desconstrução de suas concepções de gênero e sua real responsabilização pelos danos como uma medida protetiva a ser pleiteada pela vítima, pelo Ministério Público ou pela autoridade policial e a ser deferida juntamente com as demais pelo magistrado competente.

Desse modo, conclui-se que o uso de tal obrigatoriedade como uma política criminal extrapenal, observando-se as origens sócio-histórico-culturais da agressão a mulheres em ambiente familiar e doméstico tem maior condão de cumprir as finalidades propostas pela Lei Maria da Penha, assim como, a longo prazo, responder aos anseios populares, transmutando-se a aplicação da Lei a fins meramente 
midiáticos e simbólicos a uma efetiva utilização do texto legal para diminuir a situação de violência doméstica contra mulheres no Brasil.

\section{REFERÊNCIAS}

ACRE. Polícia Civil do Estado do Acre. Cartilha Conhecendo a Lei non11.340/06 Lei Maria da Penha. Acre: Secretaria de Estado de Segurança Pública, 2008.

ALVARENGA, Leonardo Davi. Criminologia Crítica Feminista e Violência Contra a Mulher: um estudo da eficácia invertida do combate à violência doméstica e familiar contra a mulher. Monografia - Faculdade de Direito de Vitória, Vitória, 2010.

ALMUDENA, García Manso; SILVA, Artenira da Silva e. Micromachismos o microtecnologias de poder: la subyugación e infravaloracíon, que mantienen el significado político y social del "ser mujer" como la desigual. CONPEDI LAW REVIEW, v. 1 , n. 3, 2015, p. 115-123.

ANDRADE, Vera Regina Pereira de. A ilusão de segurança jurídica: do controle da violência à violência do controle penal. Porto Alegre: Livraria do Advogado, 1997.

ANDRADE SILVA, Raissa. A natureza jurídica e o procedimento das medidas protetivas de urgência. Monografia - Universidade Estadual da Paraíba, 2013.

A soberania patriarcal: o sistema de justiça criminal no tratamento da violência sexual contra a mulher. Revista Sequência, n. 50, jul. 2005, p. 71-102.

AZEVEDO, Rodrigo Ghiringhelli de. Sistema Penal e Violência de Gênero: análise sociojurídica da Lei 11.340/2006. Sociedade e Estado, Brasília, v. 23, n. 1, jan./abr. 2008, p. 113-135.

BRASIL. Código Penal Imperial. Lei no 16, dezembro de 1830.

\section{Constituição da República Federativa de 1988.}

. Lei no 11.340/2006, cria mecanismos para coibir a violência doméstica e familiar contra a mulher, 07 de agosto de 2006.

CALAZANS, Myllena; CORTES, láris. O processo de criação, aprovação e implementação da Lei Maria da Penha. In: CAMPOS, Carmen Hein de. Lei Maria da Penha comentada em uma perspectiva jurídico-feminista. Rio de Janeiro: Lumen Juris, 2011.

CELMER, Elisa Girroti; AZEVEDO, Rodrigo Ghiringhelli. Violência de Gênero, Produção Legislativa e Discurso Punitivo - uma análise da Lei no 11.340/2006. Boletim IBCCRIM, ano 14, n. 170, jan. 2007. 
CENTRO FEMINISTA DE ESTUDOS E ASSESSORIA. Lei Maria da Penha: do papel para a vida. 2 ed. Brasília: CFEMEA, 2009.

CIT, Franciele. Tendências da Política Criminal no Estado Democrático de Direito Brasileiro: Enfoque Minimalista Consubstanciado na Constituição de 1988. Revista da ESMESC, v. 17, n. 23, 2010, p. 231-258.

CHRISTIE, Nils. A suitable amount of crime. In: Key Readings in Criminology. Devon, UK: Willan Publishing, 2009, p. 17-18.

DIAS, Jorge Figueredo; ANDRADE, Manoel da Costa. Criminologia: o homem delinqüente e a sociedade criminógena. Coimbra: Coimbra, 1997.

DIAS, Maria Berenice. A Lei Maria da Penha na Justiça: a efetividade da Lei 11.340/2006 de combate à violência doméstica e familiar contra a mulher. São Paulo: Ed. Revista dos Tribunais, 2007.

DINIZ NETO, Eduardo. Sociedade de risco, direito penal e política criminal. Revista de Direito Público, Londrina, v. 5, n.2, ago. 2010, p. 202-220.

DURKHEIM, Émile. As regras do método sociológico. 15. ed. São Paulo: Companhia Editora Nacional, 1995.

FUNDAÇÃO PERSEU ABRAMO/SESC. Pesquisa Mulheres brasileiras e gênero nos espaços público e privado. Brasília, DF,2010. Disponível em: < http://www.agenciapatriciagalvao.org.br/dossie/pesquisas/pesquisa-mulheresbrasileiras-nos-espacos-publico-e-privado-fundacao-perseu-abramosesc-2010/>. Acesso em: 20 de out. de 2015.

GRINNOVER, Ada Pellegrini. O minissistema brasileiro de Justiça consensual: compatibilidades e incompatibilidades, In: CARMONA, Carlos Alberto. Arbitragem e processo, 3 ed., rev. e ampl., São Paulo: Atlas, 2009, p. 1-30

GUIMARAES, Cláudio Alberto Gabriel. Funções da pena privativa de liberdade no sistema penal capitalista. 2. ed., Rio de Janeiro: Revan, 2007.

Reflexões acerca do controle social formal: rediscutindo os fundamentos do direito de punir. Revista da Faculdade de Direito da UERJ. Rio de Janeiro, v.1, n.23, jun. 2013. Disponível em: < http://www.epublicacoes.uerj.br/index.php/rfduerj/article/view/4894 >. Acesso em: 18 dez. 2013.

HOLANDA, Sérgio Buarque de. Raízes do Brasil. São Paulo: Companhia das Letras, 1995.

JIMENEZ, Emiliano Borja. Sobre el concepto de política criminal - Uma aproximación a su significado desde la obra de Claus Roxin. ADPCP, vol. LVI, 2003. p. 113-150. 
LUCA, Heloisa Meroto de. A Política Criminal como critério teleológico da dogmática penal. Dissertação de Mestrado - Faculdade de Direito da Universidade de São Paulo, 2009.

MARTINS, Ana Carolina Fiúza Pesca de Sousa. Violência conjugal: a psicopatia numa amostra de agressores encarcerados. Dissertação de Mestrado - Universidade Lusófona de Humanidades e Tecnologias, Lisboa, 2013.

MIRANDA SANTOS, Bartira Macedo de. A Moderna Ciência Penal: a especialização dos saberes e sua função ideológica. XXII Encontro Nacional do Conpedi/UNINOVE, 2013, p. 507-529.

MORAES, Maurício Zanoide de. Política Criminal, Constituição e Processo Penal: Razões da Caminhada Brasileira para a Institucional do Caos. Revista da Faculdade de Direito da Universidade de São Paulo, vol. 101, jan./dez. 2006, p. 403-430.

NEWBURN, Tim. Criminology. London: Willan Publishing, 2007.

NORONHA, Adriana Vidal de; NORONHA, Joanna Vieira. Afinal, o que é mulher? E quem foi que disse?. Revista Direito e Práxis, Rio de Janeiro, v. 7, n. 15, 2016, p. 741-776.

OLIVEIRA, Leidiane Souza de. A Lei Maria da Penha (11.340/2006) como estratégia de garantia dos direitos das mulheres vítimas de violência no Brasil. In: Jornada Internacional de Políticas Públicas, 6, São Luís-MA, 2013. Neoliberalismo e Lutas Sociais: perspectivas para as políticas públicas. São Luís, 2013.

PIRES, Amom Albernaz. A opção legislativa pela Política Criminal Extrapenal e a Natureza Jurídica das Medidas Protetivas da Lei Maria da Penha. Revista Ministério Público Distrito Federal e Território, Brasília, v.1, n.5, 2011, p. 121-168

PRESIDÊNCIA DA REPÚLICA. Diretrizes para Implementação dos Serviços de Responsabilização e Educação de Agressores, 2008.

RADFORD, Jill; STANKO, Elisabeth A. Violence against women and children: the contradictions of crime control under patriarchy. In: Key Readings in Criminology. Devon, UK: Willan Publishing, 2009, p. 402-140.

ROXIN, Claus. Estudos de Direito Penal. Rio de Janeiro: Renovar, 2006.

SAFFIOTI, Heleieth. Contribuições feministas para o estudo da Violência de Gênero. Cadernos Pagu, Campinas, n. 16, 2001. Paulo, 2004.

Gênero, patriarcado, violência. Editora Fundação Perseu Abramo: São

Violência estrutural e de gênero - Mulher gosta de apanhar?. In: PRESIDÊNCIA DA REPÚBLICA. Programa de Prevenção, Assistência e Combate 
à Violência Contra Mulher - Plano Nacional: Diálogos sobre Violência Doméstica e de Gênero - construindo políticas públicas, 2003, p. 27-38.

SANTOS, Andréia Colhado Gallo Greco; SANTOS, Bruno Baltazar dos. Do simbolismo penal e da lei maria da penha: a (in)efetiva proteção da mulher. 2013. Disponível em: < http://www.publicadireito.com.br/artigos/?cod=185e48a43c7f63ac >. Acesso em: 18 out. 2013.

SAUÁIA, Artenira Silva; ALVES, José Márcio Maia. A tipificação da "lesão à saúde psicológica": revisitando o artigo 129, do Código Penal à luz da Lei Maria da Penha. XXV Encontro Nacional do Conpedi, Brasília, 2016, p. 77-96.

; ARRUDA, Maurilene de Andrade Lima Bacelar de; MELO, Jonhnny Welton Feitosa. Seguimento Psicológico para agressores domésticos de crianças: protocolo de atendimento psicoterápico breve. Revista Brasileira med fam comunidade, ano 6, n. 21, Florianópolis, out./dez. de 2011, p. 1-7.

SILVA SANCHÉZ, Jésus-María. Aproximação ao Direito Penal Contemporâneo. São Paulo: Revista dos Tribunais, 2011.

YACOBUCCI, Guillermo J. La deslegitimación de la potestad penal. Buenos Aires: Ábaco, 2000.

ZAFFARONI, Eugenio Raul. La globalización y las actuales orientaciones de la política criminal. In: COPETTI, André. (Org.). Criminalidade Moderna e Reformas Penais. Estudos em homenagem ao Prof. Luis Luisi. Porto Alegre: Livraria do Advogado, 2001. Revan, 2003.

et al. Direito Penal brasileiro. Teoria geral do Direito Penal. Rio de Janeiro: 